\title{
Design Methods for Reconfigurable Filters: A Review
}

\author{
${ }^{1}$ Mr. Sunil Gagare, ${ }^{2}$ Dr. Dolly Reney \\ ${ }^{1}$ Research Scholar, ${ }^{2}$ Associate Professor, Department of Electrical and Electronics Engineering, \\ Oriental University, Indore, Madhya Pradesh-453555, India \\ E-mail: ${ }^{1}$ sunilgagare@yahoo.co.in, ${ }^{2}$ d_reney@ rediffmail.com
} Received July 15, 2019; received in revised form July 25, 2019; Accepted July, 28, 2019

Available online July, 2019

\begin{abstract}
The new design methods of microwave filter has proved its significance for use in wireless communication systems. Modern wireless communication systems require microwave filters to have stringent specifications such as compact size, robust, conformal, light weight and more importantly cost effective while maintaining its electrical characteristics. Micro-strip filter design and reconfigurable filters present a better prospectus in this regard as it meets the specifications of modern wireless communication applications. Reconfigurable filters can provide control over parameters such as frequency, bandwidth and selectivity while reducing the need of number of switches sandwiched between electrical components. Different methods have provided a new dimension for designing microwave filters. In this article, we present a review on design methods for reconfigurable band-pass filters for next generation wireless technologies such as 4G, $5 \mathrm{G}$ and IOT.
\end{abstract}

Keywords: Reconfigurable Filters, Microwave filter, Wireless communication, Micro-strip filter design

\section{Introduction}

Use of wireless communication systems has transformed our life style over the last few decades, and no mystery, with more advances in wireless communication system the next decade shall be revolutionary. Technologies such as 4G, 5G and IOT have already started impacting our life style through concepts of smart cities, smart grid systems and smart factories. Each wireless application demands different requirement based on the operational frequency, modulation schemes used, data rate, transmission bandwidth, power consumption and coverage area. A typical receiver in a wireless system is as shown in Fig. 1. Design of all components becomes crucial for errorless and effective reception of the transmitted signal.

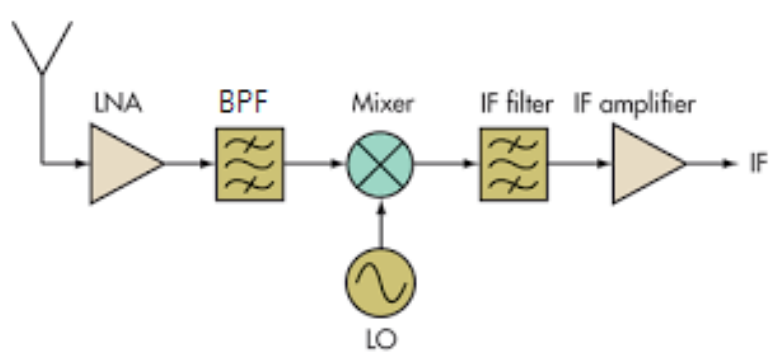

Figure 1 Typical block diagram of wireless receiver system

The receiving antenna receives the signal while the low noise amplifier (LNA) amplifies the signal without amplifying the noise signal. The obvious application of the filter structure in such scenario is to reject the unwanted signal (the noise signal as well as the unwanted frequency signals) while permitting good transmission of wanted frequencies [1]. The most common filters deployed in various 
scenarios are low-pass, high-pass, band-pass or band-stop [2].

With rapid development in MMIC (Monolithic Microwave Integrated Circuits) and HIC (Hybrid Integrated Circuit) technologies, development of filters having stringent specifications such as good counterfeit free response, fine/ ample bandwidth, good in band performance while maintaining compact size and low cost. Waveguide cavities have been used for the design of filters with good pass band and stop band roll off characteristics [2][5] however; they have a limited practical application usage due to low quality factor and difficulty in fabrication [6]. The requirement of high-quality factor and low loss can be achieved by using substrate integrated waveguide (SIW) for design and development of high-performance band-pass filters [7]-[8]. Dielectric resonator-based filter offers advantages of compact size, high quality factor making it suitable candidate for propose and expansion of high-performance RF/ Microwave filters [9]-[10]. Further development in filter microwave design based on concepts of single band-pass and differential band-pass filters has been illustrated in [11]-[12] using dielectric resonators. Micro-strip line based band-pass filters offer advantages such as light weight, compact, robust and conformal structure, low profile and easy integration with MMIC chips have been proposed in[13]-[14] [Fig. 2 a) and b)]. The above-mentioned filter designs have fixed characteristics such as band-pass frequencies and quality (Q) factor. However, modern communication systems demand filters to have variable characteristics so that the same filter structure can be used for various wireless applications. Reconfigurable filters have been grossing interest amongst researchers that can provide an effective solution to the demands of the next generation wireless technologies. In this paper a detailed literature review on recent developments in reconfigurable band-pass filters has been investigated.

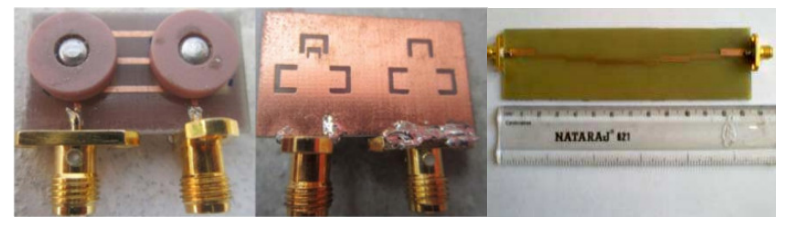

(a)

(b)

Figure 2 a) Two pole dielectric resonator band-pass filter [11], b) Micro-strip line based band-pass filter [14].

\section{Contributions}

The objective of this article is to study and identify the challenges in the design and analysis of band-pass filters specifically for next generation wireless applications and corresponding opportunities for innovative design solutions. The main contributions are as follows:

- Literature review for identifying current research developments in band-pass filter design.

- Identify gaps in research through detailed literature review and challenges in bandpass filter design for next generation wireless applications.

- Opportunities for RF engineers in developing innovative design solutions to meet specifications of band-pass filter.

\section{Reconfigurable Bandpass Filter Design}

As stated earlier, next generation wireless communication systems demand diversity in filter performance which can be achieved by using a reconfigurable filter. The term "reconfigurability" is defined as capability of filter to change its electrical characteristics (such as frequency, phase or Q-factor) by some 
means to accommodate the changing need of communication system. Traditional filter designed using waveguides, SIW and microstrip line occupy more space on the circuit boards thereby demanding use of compact and high-performance tunable filters. To select a suitable reconfiguration technique RF engineers should take into consideration of following parameters: operating frequency, physical size, performance and power handling [15]. Reconfiguration in filter can be achieved by:

- Electrically using PIN diodes, RF diodes, MEMS switch or varactors.

- Optically using photoconductivity

- Physically using structure alteration

- Materially by changing substrate material or dielectric properties of materials (i.e., by using meta materials)

Most researchers have investigated tunable band-pass and band-stop microwave filters using varactor diodes in (Fig. 3) [16]. However, less investigation of low pass filter and high pass filter using varactor diode has been carried out due to it deficiency in practical realization of monolithic reconfigurable inductor solutions that increases design complexity for achieving good performance for the design. In general, researchers have devoted their research scope in designing reconfigurable band-pass and bandstop filters which frequency and bandwidth reconfigurable characteristics. Amongst most prominently used methods, $\lambda / 2$ and $\lambda / 4$ wavelength tune able filters with varactor diodes and multi-mode filters have been commonly deployed due to its compact size and simplicity in tuning.
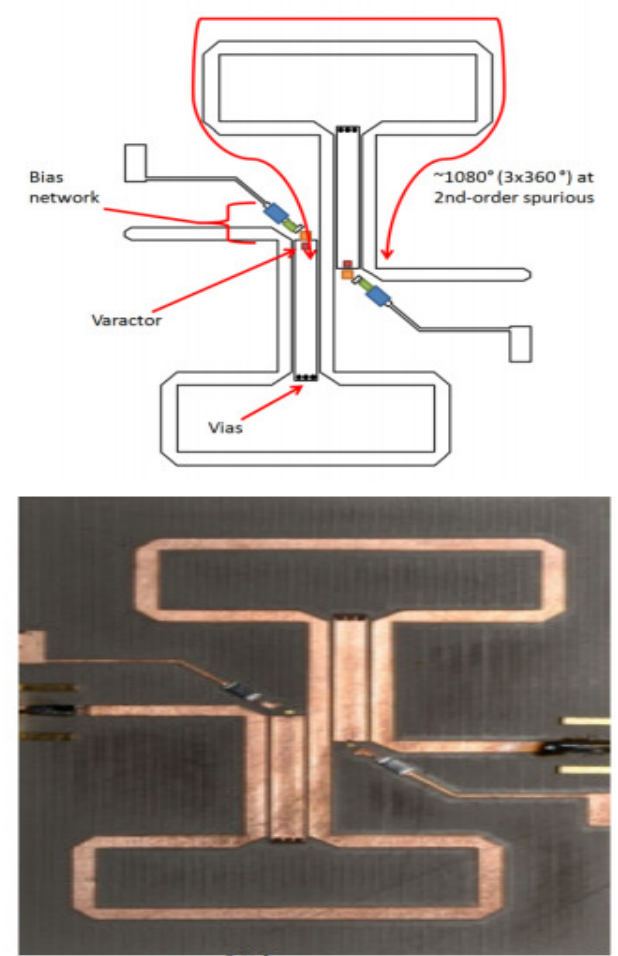

Figure 3 Tunable band-pass filter using varactor diode [18]

The next generation wireless technologies such as $4 \mathrm{G}$ and $5 \mathrm{G}$ uses carrier aggregation wherein several distinct RF carriers are allowed to be used in collaboration for the delivery and reception of data services. This method provides increased data rates in $4 \mathrm{G}$ and $5 \mathrm{G}$ technologies as compared to $3 \mathrm{G}$. When several distinct RF carriers are used, a single band-pass filter or multi-mode band-pass filter cannot be deployed in this situation. Deploying several filters to filter each distinct frequency will utilize more space on the circuit board. Also increasing RF noise in communication systems is an alarming concern for RF engineers. A reconfigurable band-pass filter providing frequency reconfigurable characteristics over the desired frequency is a suitable solution for this scenario. 


\section{A Review of recently published articles are shown below:}

Table 1 A Review of recently published articles

\begin{tabular}{|c|c|c|c|c|}
\hline Sr. No. & Authors & Paper Title \&Year & Methodology & Result \\
\hline 01 & $\begin{array}{l}\text { Roberto Gomez- } \\
\text { Garcia1, Jose- } \\
\text { Marıa Munoz- } \\
\text { Ferreras, and } \\
\text { Dimitra } \\
\text { Psychogiou, }\end{array}$ & $\begin{array}{l}\text { "Fully-Reconfigurable Band pass } \\
\text { Filter With Static Couplings And } \\
\text { Intrinsic-Switching Capabilities", } \\
2017 \text { IEEE MTT-S International } \\
\text { Microwave Symposium (IMS). }\end{array}$ & $\begin{array}{l}\text { Switching type } \\
\text { band pass filter. }\end{array}$ & $\begin{array}{l}\text { The devised fully reconfigurable } \\
\text { filter is based on a resonator- } \\
\text { cascade structure with static } \\
\text { impedance inverters and only } \\
\text { exploits the tuning of its } \\
\text { resonating nodes to achieve all its } \\
\text { reconfiguration properties. }\end{array}$ \\
\hline 02 & $\begin{array}{l}\text { Jai Utkarsh, } \\
\text { Aman Kumar } \\
\text { Lall, D. K. } \\
\text { Upadhyay, G. K. } \\
\text { Mishra }\end{array}$ & $\begin{array}{lrr}\text { "Frequency Reconfigurable } & \text { Band } \\
\text { pass Filter } & \text { For } & \text { IMT-A } \\
\text { Applications", } & \text { 2017, } & \text { 2nd } \\
\text { International Conference on } & \text { on } \\
\text { Computing and } & \text { Communications } \\
\text { Technologies } & \text { (ICCCT),IEEE } \\
\text { Explorer. } & & \\
\end{array}$ & $\begin{array}{l}\text { Spiral resonator } \\
\text { reconfigurable } \\
\text { micro strip band } \\
\text { pass filter. }\end{array}$ & $\begin{array}{l}\text { Focused on a spiral resonator } \\
\text { reconfigurable micro strip band } \\
\text { pass filter. The filter provides } \\
\text { control variation in resonance } \\
\text { frequency }(f c) \text {. }\end{array}$ \\
\hline 03 & $\begin{array}{l}\text { Mukesh Kumar } \\
\text { Khandelwal, } \\
\text { Binod Kumar } \\
\text { Kanaujia [22] }\end{array}$ & $\begin{array}{l}\text { "Defected Ground Structure: } \\
\text { Fundamentals, Analysis, And } \\
\text { Applications In Modern Wireless } \\
\text { Trends" Hindawi International } \\
\text { Journal of Antennas and } \\
\text { Propagation Volume 2017, Article } \\
\text { ID 2018527. }\end{array}$ & $\begin{array}{l}\text { Defected Ground } \\
\text { Structure }\end{array}$ & $\begin{array}{l}\text { This paper presents an } \\
\text { introduction and evolution of } \\
\text { DGS and how DGS is different } \\
\text { from former technologies: PBG } \\
\text { and EBG. }\end{array}$ \\
\hline 04 & $\begin{array}{l}\text { Arjun Kumar, } \\
\text { M.V. Kartikeyan }\end{array}$ & $\begin{array}{l}\text { "Design and Realization Of Micro } \\
\text { strip Filters With New Defected } \\
\text { Ground Structure (DGS)" } \\
\text { www.elsevier.com/ locate/jestch, } \\
2017 \text {. }\end{array}$ & $\begin{array}{l}\text { Defected Ground } \\
\text { Structure }\end{array}$ & $\begin{array}{l}\text { Focused on various micro strip } \\
\text { filters, such as band pass } \\
\text { (narrow/wideband) filters, dual } \\
\text { band pass filter and low pass } \\
\text { filters, are designed with new } \\
\text { metal strips loaded defected } \\
\text { ground structure (DGS). The } \\
\text { proposed DGS, metal strips are } \\
\text { introduced in connecting slot of } \\
\text { dumbbell shaped DGS (DB- } \\
\text { DGS) }\end{array}$ \\
\hline 05 & $\begin{array}{l}\text { Muhammad } \\
\text { Rusdi, Febrin } \\
\text { Aulia Batubara, } \\
\text { Rina } \\
\text { Anugrahwaty }\end{array}$ & $\begin{array}{l}\text { "Design Of Dual-Band Bandpass } \\
\text { Filter For GSM 950 Mhz And GSM } \\
\text { 1850Mhz Applications Using } \\
\text { Lumped Component", Journal of } \\
\text { Physics: Conference Series, } 2017 .\end{array}$ & $\begin{array}{l}\text { Lumped } \\
\text { Component }\end{array}$ & $\begin{array}{l}\text { Presented a design of dual-band } \\
\text { band pass filter for GSM } \\
\text { applications, to pass signals on } \\
\text { two frequency } \\
\text { simultaneously. }\end{array}$ \\
\hline 06 & $\begin{array}{l}\text { Ben Hammadi, } \\
\text { A, Haddad, } \\
\text { F, Mhiri, M, Saad, } \\
\text { S, Besbes, K. }\end{array}$ & $\begin{array}{l}\text { "RF and microwave reconfigurable } \\
\text { bandpass filter design using } \\
\text { optimized active inductor } \\
\text { circuit. Int. Journal of RF } \\
\text { Microwave Computer Aided } \\
\text { Eng. 2018; 28:e21550. }\end{array}$ & $\begin{array}{l}\text { Active inductor } \\
\text { circuit }\end{array}$ & $\begin{array}{l}\text { Presented a complete procedure } \\
\text { to develop, design and simulate a } \\
\text { micro strip band pass filter } \\
\text { working at a center frequency of } \\
5.25 \mathrm{GHz} \text { with lower and upper } \\
\text { cut-off frequencies as } 5 \mathrm{GHz} \text { and } \\
5.5 \mathrm{GHz} \text { respectively. }\end{array}$ \\
\hline 07 & $\begin{array}{l}\text { T. K. Kataria, L. } \\
\text { Osorio, J. L. } \\
\text { Olvera Cervantes, } \\
\text { J. R. Reyes- } \\
\text { Ayona, and A. } \\
\text { Corona-Chavez }\end{array}$ & $\begin{array}{l}\text { [1] "Microfluidic Reconfigurable } \\
\text { Filter Based on Ring } \\
\text { Resonators," Progress r In } \\
\text { Electromagnetics Research } \\
\text { Letters, Vol. 79, 59-63, } 2018 . \\
\text { DOI:10.2528/PIERL18080402 }\end{array}$ & Ring resonator & $\begin{array}{l}\text { The triple band filter based on } \\
\text { dual mode ring resonators is } \\
\text { reconfigured using metal-liquid } \\
\text { switches for interconnecting } \\
\text { different resonators and feed lines } \\
\text { have been proposed. }\end{array}$ \\
\hline
\end{tabular}


A reconfigurable filter (tuned over 1.10GHzto1.38GHz) based on single-sideaccess topology is presented (Fig. 4). The center frequency of the reconfigurable filter can be shifted at a desired frequency by changing the electrical length of the ring by using capacitive tuning elements have been investigated. A proper synthesis has been developed to determine the values of the capacitive elements. This synthesis can be extended further by researchers to develop reconfigurable filters of desired characteristics. Use of varactor diode to continuously tune the center frequency of the ring filter has been demonstrated.

A band-pass filter using tuneable active inductor (TAI) can provides wide frequency continuous tuning range (FTR) [21]. The proposed filter is realized using a differential TAI (DTAI) to provide coarse and fine tuning. The coarse tuning is achieved using a controllable current source while fine tuning is achieved through a variable feedback resistance. The band-pass filter is simulated using a $0.13 \mu \mathrm{m}$ CMOS technology and has an insertion loss of 23.62 to $33.45 \mathrm{~dB}$ over the tuneable frequency range of $1.16-3.27 \mathrm{GHz}$. The proposed band-pass filter has relative bandwidth of $1.3 \%-3.4 \%$.

Khandelwal [22], investigated a novel microfluidic based reconfigurable triple band filter operating over frequencies 1, 1.4 and 1.8 $\mathrm{GHz}$. The triple band filter based on dual mode ring resonators is reconfigured using metalliquid switches for interconnecting different resonators and feed lines have been proposed. The metal liquid switches (metal liquid is forced in to active the switches) actives or deactivates the interconnection of resonators and feed lines thereby allowing tuning of center frequency of the filter as well as the external Quality (Q) factor.
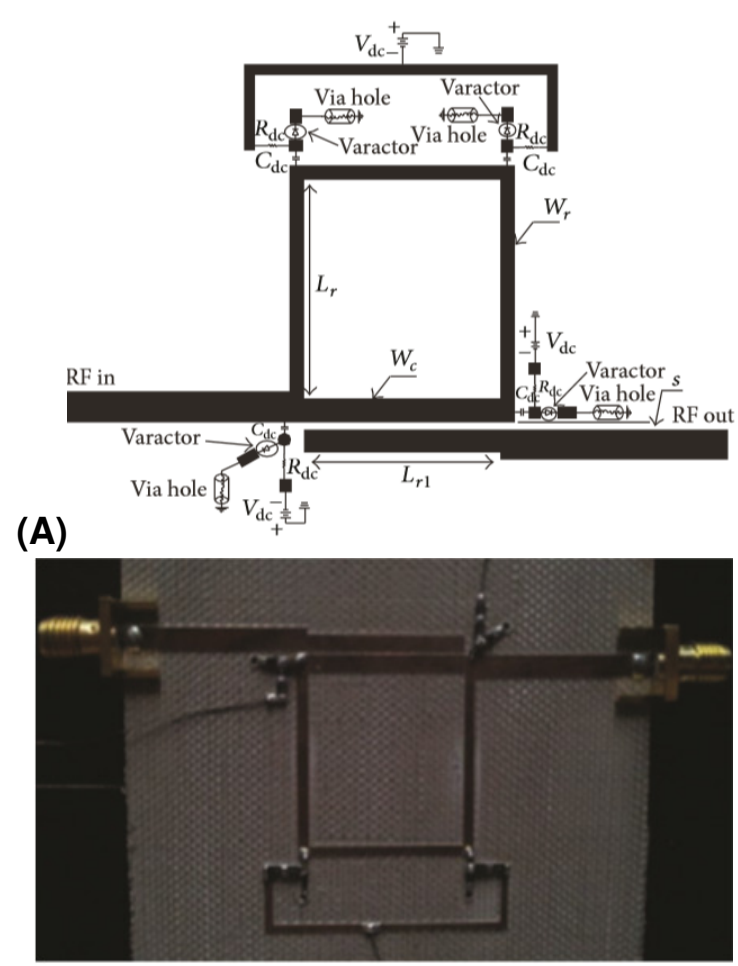

(B)

Figure 4 A reconfigurable filter based on singleside-access topology presented in [20] a) layout of the electronically reconfigurable ring band-pass filter using four skyworks SMV 1800 varactors b) fabricated prototype

A dual mode dual band waveguide band-pass filter with tuneable over the frequency range from $8.12-8.58 \mathrm{GHz}$ and $10.22-10.68 \mathrm{GHz}$ is presented in Fig. 5 [23]. Varactor diode and chip capacitor loaded planar split ring resonators in the form of filter are placed in a waveguide to provide the dual band operation. The proposed band-pass filter is compact, lightweight and provides dual mode, dual band frequency reconfigurable characteristics with insertion loss of 2.59 and $2.75 \mathrm{~dB}$, respectively. RF MEMS based electrically tunable waveguide filter with high $Q$ and tuning characteristics is investigated for $\mathrm{K}$ band applications. 


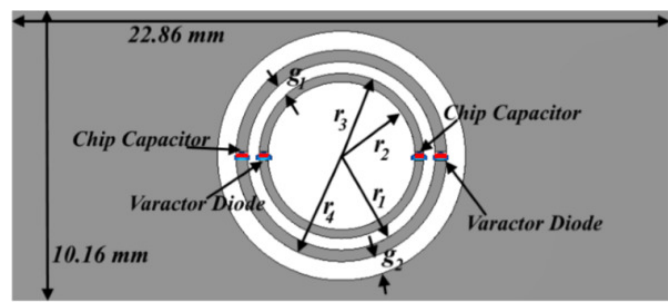

A)

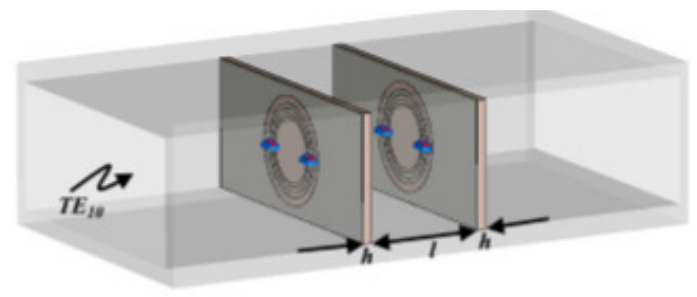

B)

C)

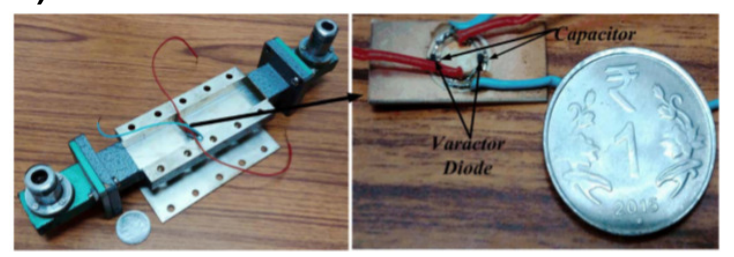

Figure 5 Dual mode dual band waveguide band-pass filter [23] a) Proposed Varactor diode and chip capacitor loaded planar split ring resonators

b) Placement of proposed ring resonator in waveguide c) Fabricated prototype with placement of ring resonator inside WR-90 waveguide.

High quality factor be achieved by using waveguide structures while high frequency tunability can be achieved by deploying radio frequency microelectro-mechanical systems (RF MEMS). In this paper, high frequency tunability of the order of 5\% while Q factor of the order of 1000 can has been achieved using combination of waveguide and MEMS structures (Fig. 6).

So far electronically tunable reconfigurable filters have been investigated. Other techniques used to achieve reconfiguration consist of using optical switches.

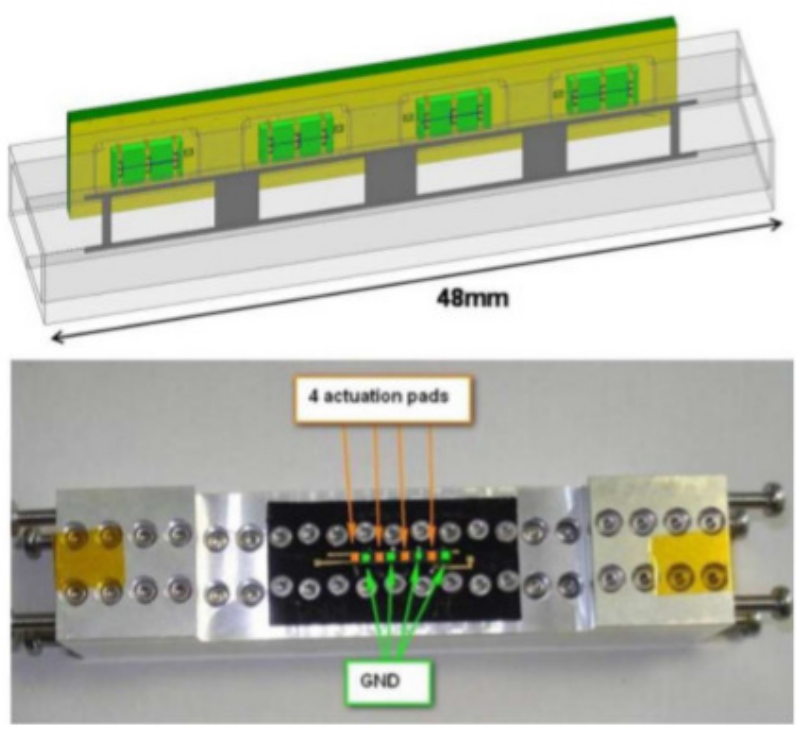

Figure 6 HFSS simulation model and fabricated prototype of RF MEMS based electrically tunable wave guide filter [24]

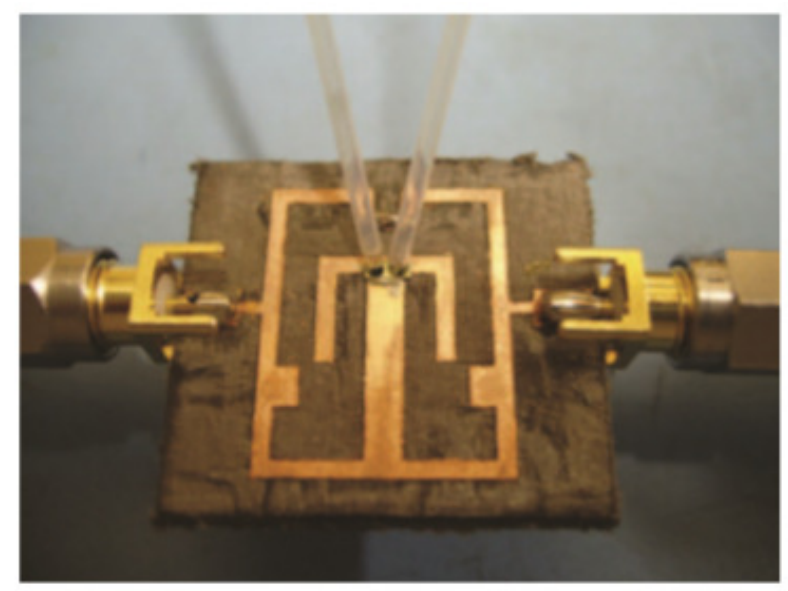

Figure 7 Fabricated prototype of optically reconfigurable Microstrip UWBB and pass Filter [25]

A UWB reconfigurable band-pass filter using optical switches has been investigated in [25] as shown in Fig. 7. A single optical switch activated using near infra-red light is deployed to select between either band-pass or band-stop response. When the optical switch is activated (in ON state) the filter circuit acts as a bandpass filter while in its deactivated state (OFF state) it acts as a band-stop filter. 


\section{Challenges and Opportunities}

a) Challenges: A critical literature review on recent advancements in design of reconfigurable band-pass filters has been presented in the previous section. Various methods to achieve reconfigurable characteristics using PIN diode, varactors, MEMS switches and optical switches have been investigated by researchers. While major focus of researchers is devoted in designing reconfigurable filter structures having less attention has been given to achieve other requirements of next generation wireless communication systems.

\section{References}

[1] Zakaria, Z., Omar, N., Othman, A. R., Jawad, M., Ismail, A., Salleh, A., \& Sam, W. (2013). Recent trends on dual-and triple-band microwave filters for wireless communications. Australian Journal of Basic and Applied Sciences, 7(10), 235-243.

[2] Hong, J. S. G., \& Lancaster, M. J. "Microstrip Filters for RF/Microwave Applications", John Wiley \& Sons, Inc., 2001. doi:10.1002/0471221619

[3] Matthaei, G., Jones, E., Young, L., and Jones, E. M. T. (1964) "Microwave Filters, ImpedanceMatching Networks and Coupling Structures", New York: McGraw-Hill.

[4] Hunter, I. C., Billonet, L., Jarry, B., \& Guillon, P. (2002). Microwave filters-applications and technology. IEEE Transactions on Microwave Theory and Techniques, 50(3), 794-805.

[5] Swanson, D. G. (2007). Narrow-band microwave filter design. IEEE Microwave magazine, 8(5), 105-114.

[6] Kishor, J., Kanaujia, B., Dwari, S., et al. (2016). Narrow-Band Bandpass Filter for Wireless Communication System. Frequenz, 71(7-8), pp. 335-340. Retrieved 13 Jun. 2019, from DOI:10.1515/freq-2016-0090.

[7] Chen, X., Hong, W., Cui, T., \& Wu, K. (2005). Substrate integrated waveguide (SIW) asymmetric dual-mode filter and b) Opportunities: Metamaterials exhibit numerous properties that have smooth path for innovative filter design solutions. The zeroindex property of metamaterials not only permits the development highly compact and efficient filters but also provides filters with reduced spurious radiation, high $\mathrm{Q}$ factor and low loss, thereby enhancing the performance in comparison to conventional material-loaded filters [26]-[27]. Using metamaterial in filter design can provide new innovative design solutions.

\section{Conflict of interest}

The author declares no conflict of interest.

diplexer. International journal of electronics, 92(12), 743-753.

[8] Zhu, X. C., Hong, W., Wu, K., Tang, H. J., Hao, Z. C., Chen, J. X., \& Chu, P. (2013). Design and implementation of a triple-mode planar filter. IEEE Microwave and Wireless Components Letters, 23(5), 243-245.

[9] Wang, C. and Zaki, K. A. (2007). "Dielectric resonators and filters," IEEE Microw. Mag., 8(5), 115-127.

[10] Tomassoni, C., Bastioli, S., \& Snyder, R. V. (2015). Propagating waveguide filters using dielectric resonators. IEEE Transactions on Microwave Theory and Techniques, 63(12), 4366-4375.

[11] Kishor, J., Kanaujia, B. K., Dwari, S., \& Kumar, A. (2016). Bandpass filter using dielectric resonator with transmission zeros. Microwave and Optical Technology Letters, 58(7), 1583-1586.

[12] Chen, J. X., Zhan, Y., Qin, W., Bao, Z. H., \& Xue, Q. (2015). Novel narrow-band balanced bandpass filter using rectangular dielectric resonator. IEEE Microwave and Wireless Components Letters, 25(5), 289-291.

[13] Kumar, D., \& De, A. (2013, December). Band pass filter design using micro strip line loaded with open stepped impedance structure. 
In IEEE MTT-S International Microwave and RF Conference (pp. 1-4). IEEE.

[14] Tiwary, A. K., \& Gupta, N. (2011). Design of compact coupled micro strip line band pass filter with improved stop band characteristics. Progress In Electromagnetics Research, 24, 97-109.

[15] Al-Yasir, Y.I.A.; Ojaroudi archin, N.; AbdAlhameed, R.A.; Abdulkhaleq, A.M.; Noras, J.M. Recent Progress in the Design of $4 \mathrm{G} / 5 \mathrm{G}$ Reconfigurable Filters. Electronics 2019, 8, 114.

[16] Wang, X.; Wang, B.; Zhang, H.; Chen, K.J. (2007). A Tunable Band-stop Resonator Based on a Compact Slotted Ground Structure. IEEE Trans. Microw. Theory Tech. 55, 1912-1918.

[17] Wang, Z.P.; Kelly, J.; Hall, P.S. Reconfigurable band-stop filter with wide tuning range. Electron. Lett. 2010, 46, 771772.

[18] Guyette, A.C. (2010). Design of fixed- and varactor-tuned band-stop filters with spurious suppression. In Proceedings of the 40th European Microwave Conference, Paris, France, 28-30 September; 288-291.

[19] Huang, C.; Chen, N.; Tsai, H.; Chen, J.( 2013). A coplanar waveguide bandwidth-tuneable low-pass filter with broadband rejection. IEEE Microw. Wirel. Compon. Lett. 23, 134-136.

[20] Roberto Gomez-Garcia1, Jose-Marı MunozFerreras, and Dimitra Psychogiou, "FullyReconfigurable Bandpass Filter With Static Couplings And Intrinsic-Switching Capabilities", 2017 IEEE MTT-S International Microwave Symposium (IMS).

[21] Jai Utkarsh, Aman Kumar Lall, D. K. Upadhyay, G. K. Mishra, "Frequency Reconfigurable Bandpass Filter For IMT-A Applications", 2017, 2nd International Conference on Computing and Communications Technologies (ICCCT),IEEE Explorer.

[22] Khandelwal, M. K., Kanaujia, B. K., \& Kumar, S. (2017). Defected ground structure: fundamentals, analysis, and applications in modern wireless trends. International Journal of Antennas and Propagation, 2017.

[23] Kumar, A., \& Kartikeyan, M. V. (2017). Design and realization of microstrip filters with new defected ground structure (DGS).
Engineering Science and Technology, an International Journal, 20(2), 679-686.

[24] Muhammad Rusdi, Febrin Aulia Batubara, Rina Anugrahwaty, "Design Of Dual-Band Bandpass Filter For GSM 950 MHz And GSM $1850 \mathrm{Mhz}$ Applications Using Lumped Component", Journal of Physics: Conference Series, 2017.

[25] Ben Hammadi, A, Haddad, F, Mhiri, M, Saad, $\mathrm{S}$, Besbes, K. "RF and microwave reconfigurable bandpass filter design using optimized active inductor circuit. Int. Journal of RF Microwave Computer Aided Eng. 2018; 28: e21550.

[26] Kataria, T. K., Osorio, L., Olvera Cervantes, J. L., Reyes-Ayona, J. R., \& Corona-Chavez, A. (2018). Microfluidic Reconfigurable Filter Based on Ring Resonators. Progress In Electromagnetics Research, 79, 59-63. 